\title{
Comparative Regulatory Effects of Morus Alba Leaf Extracts on Hepatic Enzymes in Streptozotocin-Induced Diabetic and Non-Diabetic Rats
}

Mahmood Nazari', Mohammad Reza Hajizadeh ${ }^{1}$, Abrahim Eftekhar ${ }^{2}$, Shirin Fattahpour ${ }^{1}$, Hassan Ziaaddini ${ }^{3}$, Gholamhossein Hassanshahi ${ }^{4}$ Mehdi Mahmoodi ${ }^{14 *}$ and Mohsen Rezaeian ${ }^{5}$

${ }^{1}$ Department of Biochemistry Biophysics \& Genetics, Rafsanjan University of Medical Sciences, Rafsanjan, Iran

${ }^{2}$ Department of Biochemistry, Hormozgan University of Medical Sciences, Bandar Abbas, Iran

${ }^{3}$ Associate professor, Neuroscience Research Center and school of Medicine, Kerman University of Medical Sciences, Kerman, Iran

${ }^{4}$ Molecular Medicine Research Center, Rafsanjan University of Medical Sciences, Rafsanjan-Iran

${ }^{5}$ Department of Social Medicine, Rafsanjan University of Medical Sciences, Rafsanjan-Iran

\begin{abstract}
Aim and objectives: Diabetes is a metabolic disorder with hyperglycemia due to defects in insulin secretion and function. Several studies investigated the both effects of traditional herbal medicine in diabetes treatment. Therefore, the aim of the present study was to investigate the effects of Morus Alba leaf Extracts (MAE) on hepatic enzyme activity in normal and streptozotocin-induced diabetic rats.

Methods: Forty healthy adult male Wistar rats weighing $250 \pm 10 \mathrm{gr}$ were taken for this experiment. Rats were divided into 4 groups (10 rats in each group). Animals treated by a gavage tube for a period of two months as follow: group I: non diabetic control rats which only received distilled water; group II: non-diabetic rats that received (MAE) $1.0 \mathrm{~g} / \mathrm{kg}$ per day; group III: diabetic control rats treated with distilled water and group IV: Diabetic rats which received MAE $1.0 \mathrm{~g} / \mathrm{kg}$ per day. At the end of the 8th week, blood samples were collected and serum levels of enzymes alanine aminotransferase (ALT), aspartate aminotransferase (AST), alkaline phosphatase (ALP), lactate dehydrogenase $(\mathrm{LDH})$, and total bilirubin were measured in all study groups using commercial assay kits. The activity of two antioxidant enzymes including glutathione peroxidase (GPX) and glutathione reductase (GR) were also measured.

Results: Findings of present study demonstrated that MAE significantly decreased serum levels of liver enzymes ALT, AST and ALP in diabetic rats in compare to the diabetic control groups while it increased GPX and GR activity $(P<0.05)$. These results also indicated that MAE did not significantly affect $L D H$ activity in diabetic rats treated with MAE in compared to the diabetic control groups.

Conclusions: According to the present findings it could possibility be suggested that the anti-hyperglycemic effect of MAE is mediated at least partially by increasing liver GPX and GR activity as well as decrease serum levels of liver enzymes ALT, AST and ALP. These results are the other definite evidence supporting MA as traditional medicine for diabetic patients.
\end{abstract}

Keywords: Morus Alba (Mulberry) leaf; Type 1 diabetes; Liver enzymes

\section{Introduction}

According to the WHO reports, the diabetes mellitus (DM) will be the single largest non-communicable disease worldwide by the year 2025 with the largest diabetic population in India [1]. DM is a common disease in the world, with an increase in blood glucose, lipid and carbohydrate metabolism is impaired. An estimated 17 million people with diabetes in the world (2.4\%) in 2000 to 366 million (4.4\%) reached in 2030 [2]. Evidences suggest that oxidative stress and free radical production play important roles in diabetes and its pathogenesis [3].The role of free radicals in tissue damage in streptozotocin-induced diabetic rats has also been demonstrated [4]. Liver is effectively maintain normal blood glucose levels and hyperglycemia leading to an imbalance in the reduction of oxidation reactions in the hepatocytes [5]. Thus it is appears that the diabetic liver injury is induced by a several factors and cannot be controlled only with inhibiting hyperglycemia [6]. In other words, although in the early stages of diabetes, hyperglycemia-induced liver injury, occurs but its progression is linked to the maintenance of hyperglycemia [7]. Thus, controlling of blood glucose alone is not sufficient to delay or prevent diabetes complications. Living cells are protecting (by their multiple mechanisms against damage) from free radicals. Antioxidant enzymes Superoxide Dismutase (SOD), catalase, glutathione reductase and glutathione peroxidase play a pivotal role in this regard. One important strategy of the areas of research in diabetes treatment is reducing the amount of free radicals [8]. In this regard, the effects of antioxidants in preventing or reducing damage from free radicals in diabetes have been investigated [9]. Therefore, a promising drug for the treatment of diabetes should ideally have both hypoglycemic and antioxidant properties. Synthetic drugs in lowering blood glucose, not only are unable to control tissue damages in this disease but they also can cause many side effects [6]. Thus, pharmaceutical science saves looking for ways to be able to develop medication with minimal side effects. At present, consumption of herbal and natural medicines are more popular than synthetic drugs and this is an issue that is very important. Plants that we know as herbal plant compounds are numerous. These compounds together create a balanced situation and in this situation, none of the possessor compounds would have detrimental effects. Because they modify other properties and some compounds have the

*Corresponding author: Mahmood Nazari, Molecular Medicine Research Center and Deptartment of Biochemistry, Faculty of Medicine, Rafsanjan University of Medical Sciences, Rafsanjan, Iran, Tel: 0098913191 4855; Fax: 0098391522 5209; E-mail:mahmoodies@yahoo.com

Received February 10, 2014; Accepted March 26, 2014; Published March 28, 2014

Citation: Nazari M, Hajizadeh MR, Eftekhar A, Fattahpour S, Ziaaddini H, et al. (2014) Comparative Regulatory Effects of Morus Alba Leaf Extracts on Hepatic Enzymes in Streptozotocin-Induced Diabetic and Non-Diabetic Rats. Med chem S1: 003. doi:10.4172/2161-0444.S1-003

Copyright: (C) 2014 Nazari M, et al. This is an open-access article distributed under the terms of the Creative Commons Attribution License, which permits unrestricted use, distribution, and reproduction in any medium, provided the original author and source are credited. 
same task to counteract the effects of other compounds [10]. Morus Alba (MA) is a tropical and subtropical plant that grows in many parts of Asia. The importance of medicinal plants in the treatment of diseases such as gout backs to the ancient Chinese. Additionally MA is used for high blood pressure, diabetes and bacterial infections and different parts of the plant, especially the leaves and roots are used as herbal medicines [11]. Today, more attention attracted to the leaves of this plant, in some East Asian countries, a tea-like beverage is produced and is commercially available at markets [12]. Leaves of MA contain different compounds including salt, proteins, fibers, fats, carbohydrates, vitamin $C$, $\beta$-Carotene, iron, zinc, calcium and tannic acid. In addition, compounds such as dihydroxycoumarin, prenylflavore, cudrafavone $\mathrm{B}$, Cresverato and oxyreseratrol are found to have anti-inflammatory and anti-oxidants properties that serve as free radical scavenger [13]. It has been established that plants reduce glucose, lipids, strengthening the body's antioxidant defense system and almost improve diabetes complications [14]. The MA leaf contains active compounds that can inhibit a-galactosidases such as 1-deoxynojirimycin [15], and this may aid suppression of postprandial by reducing the rate of digestion and absorption of carbohydrates from intestines [2].

\section{Materials and Methods \\ Preparation of MA leaf extract}

Leaves of MA were collected from the local farms in southeastern part of Iran (Rafsanjan, Iran) in the month of April. Following authentication by botany department of Vali-Asr University, dried MA leaves were extracted with $50 \%$ ethanol. The mixture was filtered, evaporated in vacuum evaporator (percolation method) and then lyophilized in order to obtain the dry extract [16]. Using this procedure, the yield was $22 \%$ of the starting dry weight of the leaves. The obtained MA leaf extract was kept in air-tight container at $-80^{\circ} \mathrm{C}$ for further use.

\section{Animals}

All of animal procedures were approved by the Rafsanjan University of Medical Sciences ethical committee board. Male albino Wistar rats weighting ( $250 \pm 10 \mathrm{~g})$ were obtained from the experimental animal unit, faculty of medicine, Rafsanjan University of Medical Science, Rafsanjan- Iran. They were housed in an air-conditioned room $\left(25^{\circ} \mathrm{C}\right)$, 12 hour dark/light cycle which had free access to standard diet and tap water.

\section{Induction of diabetes}

Diabetes was induced by injection of a single Intra-peritoneal dose

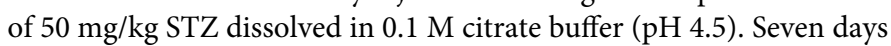
after STZ (Sigma-USA) injection, blood was collected from the animal's tail vein and fasting level of blood glucose was measured. Animals were considered as diabetic, if had a fasting blood glucose level over $300 \mathrm{mg} /$ $\mathrm{dL}$ and then were recruited in further assessments.

\section{Experimental design}

Forty healthy adult male Wistar rats (eight weeks old) were used in this experiment. Rats were divided into 4 groups (10 rats in each groups). Animals treated by a gavage tube for a period of 56 days as follow: group I: non diabetic control rats which only received distilled water; group II: non-diabetic rats that received (MAE) $1.0 \mathrm{~g} / \mathrm{kg}$ per day; group III: diabetic control rats treated with distilled water and group IV: Diabetic rats which received MAE $1.0 \mathrm{~g} / \mathrm{kg}$ per day. At the end of the $8^{\text {th }}$ week, all of rats were anesthetized and humanely killed. Blood samples were collected and the levels of aspartate aminotransferase (AST), alanine aminotransferase (ALT), alkaline phosphatase (ALP) and lactate dehydrogenase (LDH) were measured in all study groups by activity assay kit (Sigma-Aldrich) with BT-3000 auto analyzer (England). Livers were immediately excised, washed with ice cold normal saline and kept frozen at $-70^{\circ} \mathrm{C}$ until use. Liver tissue $(1 \mathrm{~g})$ were homogenized using Ultra-Turrax homogenizer in $10 \mathrm{ml}$ of normal saline and centrifuged at $8000 \mathrm{xg}$ for $15 \mathrm{~min}$ at $4^{\circ} \mathrm{C}$. The resulting supernatants were used for the determination of GPX and GR.

\section{Assay of glutathione peroxidase (GPX) and glutathione reductase activity $(\mathrm{GR})$}

These were determined according to Jakoby[17].

\section{Statistical analysis}

Data are reported as Mean \pm SEM (standard error of the mean). The difference between groups was evaluated using one-way analysis of variance (One Way ANOVA) and student t-test using SPSS version 18 statistical software. $\mathrm{P}$ values of less than 0.05 were considered significant.

\section{Results}

In the present study we examined the impacts of MAE on enzymes activity such as GR and GPX and also serum levels of AST,ALT,ALP and $\mathrm{LD}$ enzymes and $\mathrm{BT}$ and $\mathrm{BD}$ in diabetic male rats following a period of 56 days orally treatment. As shown in Figure 1, the MAE significantly enhanced GR and GPX activities in diabetic treatment group compare to control $(p<0.05)$. Our data analysis showed that the treatment of animals with MAE enhanced glutathione reductase(GR) activity in either normal or treated diabetic treatment group in compare to control $(\mathrm{p}<0.05$, Figure 1$)$. Our results also demonstrated that AST and ALT levels were significantly decreased where diabetic rats were treated with MAE $(\mathrm{p}<0.05)$, (Figure 2). Treatment of animals with MAE also significantly decreased the ALP level in diabetic MA treated rats in compare to diabetic control group $(\mathrm{P}<0.05)$ but MAE did not significantly decreased LD level in treatment group that in compared to control (Figure 3). Findings of the current study also indicated that BT (bilirubin total) and BD (bilirubin direct) serum level in treatment group in compare to control group (Figure 4). Also when animals fed with MA leaf extract the FBS level was also significantly decreased in compare to control $(\mathrm{p}<0.05)$, (Figure 5).

\section{Discussion}

Mechanisms involve in elevation of oxidative stress in diabetes are mostly auto oxidative glycosylation, nonenzymatic glycation, metabolic stress resulting from changes in energy metabolism, changes in the level of inflammatory mediators and the status of antioxidant defense systems [18]. Several serum enzymes such as ALT and AST are defined as biomarkers of hepatocellular injuries. ALP is also a favorite indicator for hepatobiliary disease. ALP is mostly accumulated within the biliary canaliculi and belonging to a group of phosphatases found in at least all of body tissues. ALT, AST, gamma-glutamyl transferase (GGT), ALP and LD enzymes are released into the circulation from the cytosol and subcellular organelles of hepatocytes, once liver is injured or damaged [19]. The relationship between glycaemic metabolic control and intracellular concentration of reduced glutathione (GSH) and related enzymes GSH-peroxidase (GSH-Px), GSH-reductase (GSH-Red), GSH-transferase (GSH-Tr), glucose-6-P-dehydrogenase (G6PDH), and thioltransferase (TT) in insulin-dependent diabetes mellitus (IDDM) patients is controversial [20]. Glutathione (GSH) is an important intracellular factor that prevents the accumulation of hydroperoxides and plays a role in formation of arachidonic acid 


\section{liver GR activity}

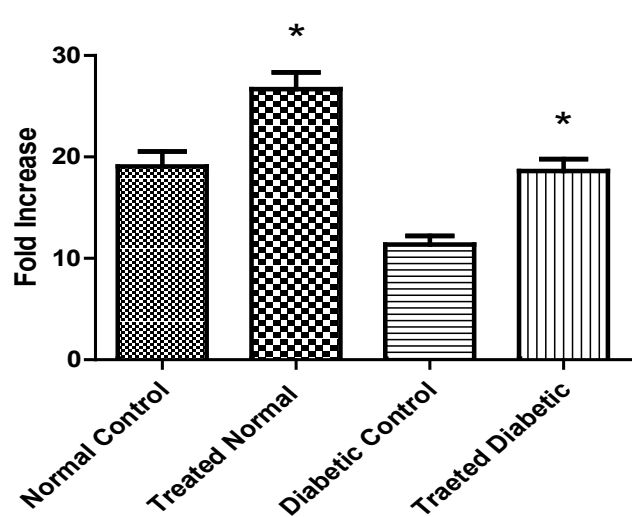

liver GPx activity

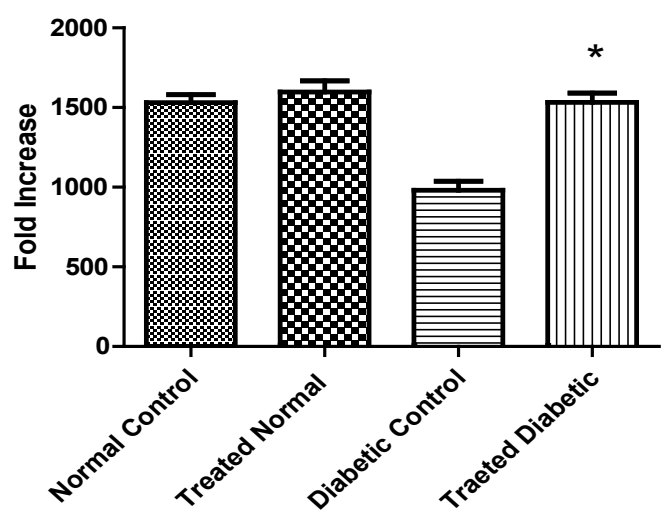

Figure 1: The effects of MA on activity of liver GPx and GR enzymes, values are Means \pm SEM. Of 12 rats in each group, MA: MORUS ALBA LEAVES EXTRACT, GPx: glutathione peroxidase, GR: glutathione reductase. " = significant difference with control subjects.

metabolites [21]. GSH biosynthesis and degradation as well as its inter-conversion from the oxidized to the reduced form is complex. Glutathione reductase (GSH-Red) catalyses' the conversion of oxidized to reduced GSH, utilizing NADPH [22] which derives from the hexose monophosphate shunt and this process is altered in diabetic individuals [23]. Our results revealed that treating the diabetic rats with MAE could significantly enhance glutathione reductase (GR) and glutathione peroxidase (GPx) activities in diabetic treatment group compared to control. Our results also revealed that diabetic rats fed with MA leaf extract had significantly decreased AST, ALT and ALP levels in diabetic treatment group compared to control. But MA leaf extract did not significantly decreased LD level in treatment group compared to control. More examinations in the field of anti-hyperglycemic properties of medicinal plants or herbal components are deserved WHO (world health organization) as the number of diabetic patients is also continuously growing. The MA extract components, especially flavonoids (i.e, quercetin, rutin, and isoquercitrin), are among free radical scavengers family and indicating the possibility of antioxidant activity [24]. Antioxidant balance is altered by reducing the activity of catalase, superoxide dismutase and glutathione peroxidase and total antioxidant levels that may lead to insufficiency of antioxidant defense against damages induced by ROS. Although, glutathione peroxidase enzyme is relatively stable, but it has been reported that is disabled at severe oxidative stress conditions [25]. Ugochukwo and colleagues showed that glutathione peroxidase activity and total antioxidant levels in diabetic rats increases [26]. The results obtained by Andallu, Sekeroglu and colleagues showed that levels of total antioxidant and glutathione peroxidase activity in diabetic mice reduced, the results of the present study also showed that reduced factors in diabetic rats [27]. Decrease in glutathione peroxidase activity may be due to glycation antioxidant enzymes by glucose [28]. Recently Grazler and colleagues shown that glutathione peroxidase by Peroxynitrite inactivated that is an oxidant potential [29]. Components of total antioxidant such as vitamin $\mathrm{E}$ and glutathione, cause removal of free radicals from the body. Thus, reduce glutathione peroxidase activity in diabetic rats which was observed in this study may reduce the total antioxidant response and thus increase the production levels of $\mathrm{H} 2 \mathrm{O} 2$ and $\mathrm{O}_{2}^{-}$via nonenzymatic glycation and auto-oxidation glucose [30]. In this study, mulberry leaf extract increased the level of enzyme activity. Studies conducted by Soo-Yeul and colleagues with flavonoid substances, indicated increased activity of glutathione peroxidase, glutathione reductase and total antioxidant levels in diabetic rats that have received these compounds [31]. Because MAE containing abundant isoflavones, it is possible role of extract in increasing glutathione peroxidase activity and plasma antioxidant levels related to neutralize free radicals, especially hydroxyl radicals. It is also probable that the extract directly activates the enzyme glutathione peroxidase or increase expression it. The antioxidant compounds
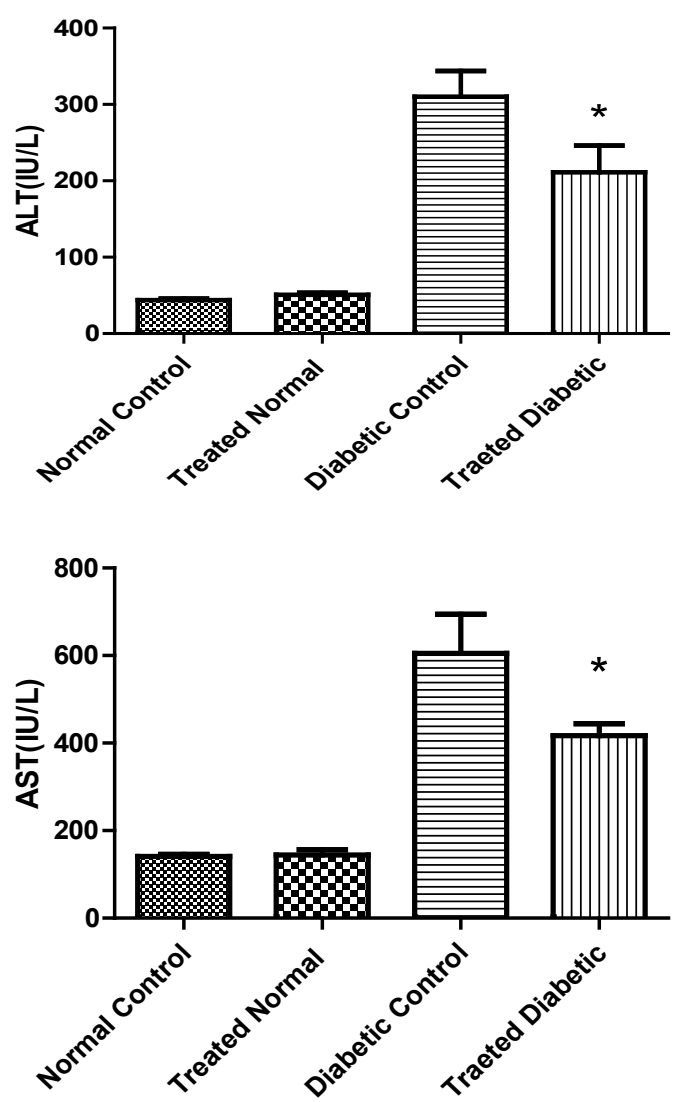

* = significant difference with control subjects

Figure 2: The effects of MA on serum levels of AST and ALT enzymes, values are Means \pm SEM. Of 12 rats in each group, MA: MORUS ALBA LEAVES EXTRACT. 

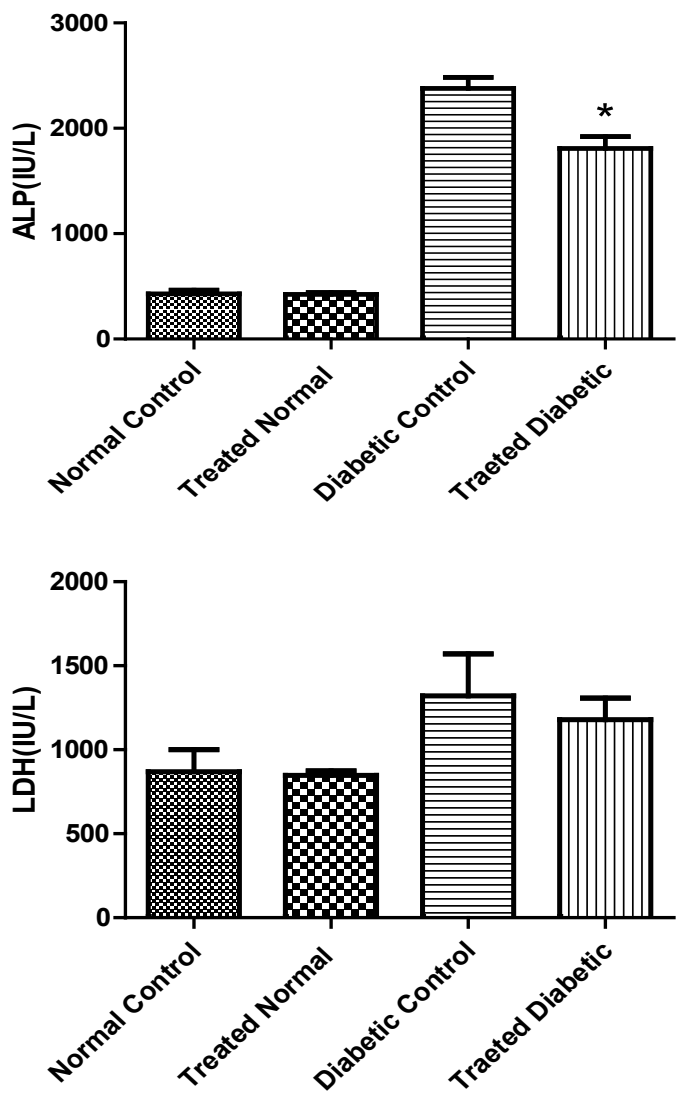

" = significant difference with control subjects

Figure 3: The effects of MA on serum levels of ALP and LDH enzymes, values are Means \pm SEM. Of 12 rats in each group, MA: MORUS ALBA LEAVES EXTRACT.

in MA enter to the circulationvia passing through small intestine, where they do perform their biological functions as antioxidant [32]. The quercetin, metabolites are produced by microbial flora of the gut and retain systemic antioxidant activity [33]. Anthocyanin is another antioxidant reagent abundantly found in wild MA fruit and is absorbed from gastrointestinal tract, which even at the trace amount, giving antioxidant activity in plasma [34]. Growing evidences are in favor of the fact that structural damage to organs and tissues, or complications of DM, could be due to oxidative stress. Oxidative stresses may also play critical part in the development of STZ-induced diabetes in one side, and mitochondrion are proposed as a target organelle or STZ-induced toxicity processes on the other side [35]. Natural polyphenols are abundant biomaterials with plant origin and thousands of polyphenols have been discovered in natural products to date. The two main types of polyphenols are flavonoids and phenolic acids [36]. Polyphenols present in food and beverage, demonstrated to have potentially health benefits due to their antioxidant activities. These polyphenols are believed to acting protect cell constituents against oxidative stress as well as controlling tissue damage by directly on reactive oxygen species or by stimulating endogenous antioxidant defense systems [37]. Consequently, they may decrease the risk of various metabolic disorders, which are closely associated with oxidative stress damage. In fact, other investigators proposed that some types of polyphenol are capable of limiting the development of DM [38], cardiovascular disease [39], and cancer [40]. It has been suggested that polyphenols may modulate hyperglycemia through various mechanisms. First, they reduce glucose absorption from intestinal mucosa and proximal renal tubule by inhibiting a-glucosidase and/or sodium-glucose symporter in the peripheral tissues [41]. Second, polyphenols decrease hepatic gluconeogenesis [42], and induce adrenergic stimulation of muscle glucose uptake [43] and pancreatic B cell insulin release [44].
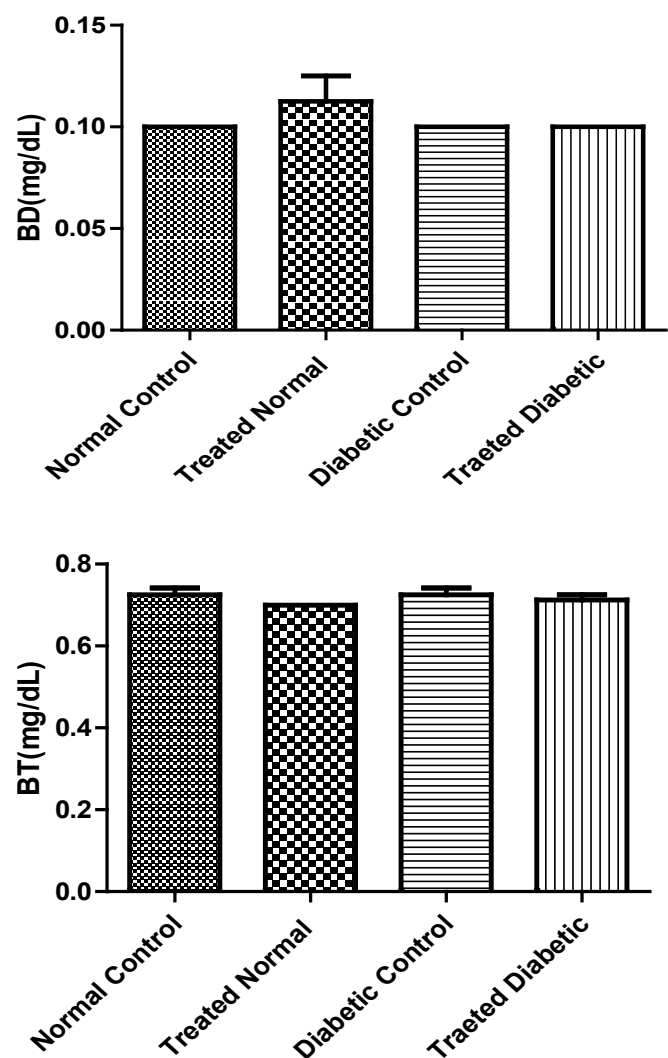

Figure 4: The effects of MA on serum levels of BT (bilirubin total) and BD (bilirubin direct) enzymes, values are Means \pm SEM of 12 rats in each group, MA: MORUS ALBA LEAVES EXTRACT.

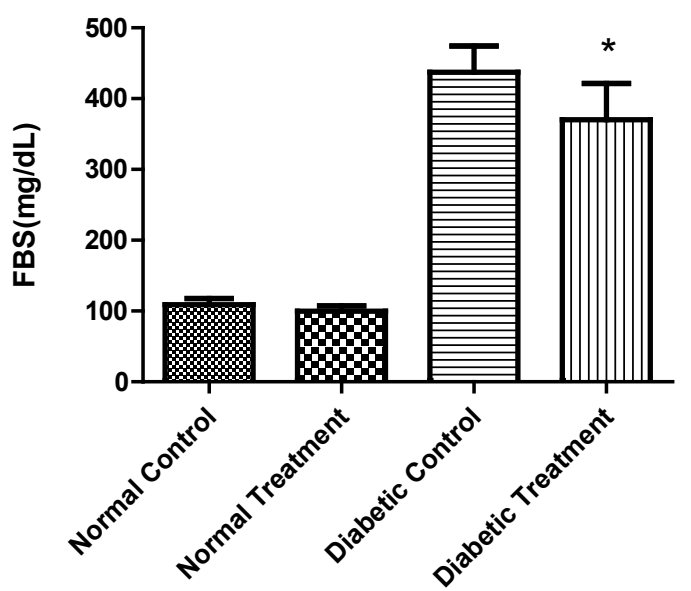

* = significant difference with control subjects

Figure 5: The effects of MA on FBS levels, values are Means \pm SEM of 12 rats in each group, MA: MORUS ALBA LEAVES EXTRACT, FBS: Fasting Blood Suger. 


\section{Concluding Remarks}

Overlay the present study, MA leaf extract was found to decrease AST, ALT, ALP and LD levels in STZ induced diabetic rats, increase and modulate the activating of glutathione reductase (GR) and glutathione peroxidase (GPx), the enzymes involved in the processes of stress oxidative. However, this work is insufficient to precisely address the exact role of MA leaf extract on DM, more well designed studies and required to evaluate mechanisms of MA action of active constituent. Our study in a way may probably confirm the antihyperglycemic and strong antioxidative effects of the MA leaf extract in diabetic rats. These results also support the role of antioxidant therapy in diabetic complications.

\section{Acknowledgements}

Author of this article take this opportunity to thanks RUMS (Rafsanjan University of Medical Sciences) for financial supports.

\section{References}

1. Lee CY, Sim SM, Cheng HM (2008) Phenylacetic acids were detected in the plasma and urine of rats administered with low-dose mulberry leaf extract. Nutr Res 28: 555-563.

2. Wild S, Roglic G, Green A, Sicree R, King H (2004) Global prevalence of diabetes: estimates for the year 2000 and projections for 2030. Diabetes Care 27: $1047-1053$

3. Cerielo A, Motz E, Cavarape A, Lizzio S, Russo A, Quatraro A, et al. (1997) Hyperglycemia counterbalances the antihypertensive effect of glutathione in diabetic patients: evidence linking hypertension and glycemia through the oxidative stress in diabetes mellitus. J Diabetes Complications 11: 250-255.

4. Murugan P, Pari L (2006) Effect of tetrahydrocurcumin on plasma antioxidants in streptozotocin-nicotinamide experimental diabetes. J Basic Clin Physiol Pharmacol 17: 231-244.

5. Cameron NE, Gibson TM, Nangle MR, Cotter MA (2005) Inhibitors of advanced glycation end product formation and neurovascular dysfunction in experimental diabetes. Ann N Y Acad Sci 1043: 784-792.

6. Liu HR, Tang XY, Dai DZ, Dai Y (2008) Ethanol extracts of Rehmannia complex (Di Huang) containing no Corni fructus improve early diabetic nephropathy by combining suppression on the ET-ROS axis with modulate hypoglycemic effect in rats. J Ethnopharmacol 118: 466-472.

7. Vestra M, Fioretto $P(2003)$ Diabetic nephropathy: renal structural studies in type 1 and type 2 diabetic patients. Internatrional Congress Series 1253: 163169.

8. Butler R, Morris AD, Belch JJ, Hill A, Struthers AD (2000) Allopurinol normalizes endothelial dysfunction in type 2 diabetics with mild hypertension. Hypertension 35: 746-751.

9. El-Bassiouni EA, Helmy MH, Abou Rawash N, El-Zoghby SM, Kamel MA, et al. (2005) Embryopathy in experimental diabetic gestation: assessment of oxidative stress and antioxidant defence. Br J Biomed Sci 62: 71-76.

10. Huwe CM (2006) Synthetic library design. Drug Discov Today 11: 763-767.

11. Butt M, Nazir A, Sultan M, Schroin K (2008) Morusalba L: naturs functional tonic. Trends Food Sci Technol 19: 505-512.

12. Kobayashi Y, Miyazawa M, Kamei A, Abe K, Kojima T (2010) Ameliorative effects of mulberry (Morus alba L.) leaves on hyperlipidemia in rats fed a high-fat diet: induction of fatty acid oxidation, inhibition of lipogenesis, and suppression of oxidative stress. Biosci Biotechnol Biochem 74: 2385-2395.

13. Oh H, Ko EK, Jun JY, Oh MH, Park SU, et al. (2002) Hepatoprotective and free radical scavenging activities of prenylflavonoids, coumarin, and stilbene from Morus alba. Planta Med 68: 932-934.

14. Naowaboot J, Pannangpetch P, Kukongviriyapan V, Kongyingyoes B, Kukongviriyapan $U$ (2009) Antihyperglycemic, antioxidant and antiglycation activities of mulberry leaf extract in streptozotocin-induced chronic diabetic rats. Plant Foods Hum Nutr 64: 116-121.

15. Davidson AL, Arion WJ (1987) Factors underlying significant underestimations of glucokinase activity in crude liver extracts: physiological implications of higher cellular activity. Arch Biochem Biophys 253: 156-167.

16. Sharma R, Sharma A, Shono T, Takasugi M, Shirata A, et al. (2001) Mulberry moracins: scavengers of UV stress-generated free radicals. Biosci Biotechnol Biochem 65: 1402-1405.

17. (1985) Glutamate, glutamine, glutathione, and related compounds. Methods Enzymol 113: 1-723.

18. Wolff SP (1993) Diabetes mellitus and free radicals. Free radicals, transition metals and oxidative stress in the aetiology of diabetes mellitus and complications. Br Med Bull 49: 642-652.

19. Ramaiah SK (2007) A toxicologist guide to the diagnostic interpretation of hepatic biochemical parameters. Food Chem Toxicol 45: 1551-1557.

20. Seghieri G, Di Simplicio P, De Giorgio LA, Anichini R, Alberti L, et al. (2000) Relationship between metabolic glycaemic control and platelet content of glutathione and its related enzymes, in insulin-dependent diabetes mellitus. Clin Chim Acta 299: 109-117.

21. Hill TD, White JG, Rao GH (1989) Role of glutathione and glutathione peroxidase in human platelet arachidonic acid metabolism. Prostaglandins 38 21-32.

22. Meister A (1985) Methods for the selective modification of glutathione metabolism and study of glutathione transport. Methods Enzymol 113: 571 585 .

23. Murakami K, Kondo T, Ohtsuka Y, Fujiwara Y, Shimada M, et al. (1989) Impairment of glutathione metabolism in erythrocytes from patients with diabetes mellitus. Metabolism 38: 753-758.

24. Hassimotto NM, Genovese MI, Lajolo FM (2008) Absorption and metabolism of cyanidin-3-glucoside and cyanidin-3-rutinoside extracted from wild mulberry (Morus nigra L.) in rats. Nutr Res 28: 198-207.

25. Condell RA, Tappel AL (1983) Evidence for suitability of glutathione peroxidase as a protective enzyme: studies of oxidative damage, renaturation, and proteolysis. Arch Biochem Biophys 223: 407-416.

26. Ugochukwu NH, Cobourne MK (2003) Modification of renal oxidative stress and lipid peroxidation in streptozotocin-induced diabetic rats treated with extracts from Gongronema latifolium leaves. Clin Chim Acta 336:73-81.

27. Andallu B, Varadacharyulu NCh (2003) Antioxidant role of mulberry (Morus indica L. Cv. Anantha) leaves in streptozotocin-diabetic rats. Clin Chim Acta 338: 3-10.

28. Armstrong AM, Chestnutt JE, Gormley MJ, Young IS (1996) The effect of dietary treatment on lipid peroxidation and antioxidant status in newly diagnosed noninsulin dependent diabetes. Free Radic Biol Med 21: 719-726.

29. Grzelak A, Soszynski M, Bartosz G (2000) Inactivation of antioxidant enzymes by peroxynitrite. Scand J Clin Lab Invest 60: 253-258.

30. Aragno M, Brignardello E, Tamagno E, Gatto V, Danni O, et al. (1997) Dehydroepiandrosterone administration prevents the oxidative damage induced by acute hyperglycemia in rats. J Endocrinol 155: 233-240.

31. Cho SY, Park JY, Park EM, Choi MS, Lee MK, et al. (2002) Alternation of hepatic antioxidant enzyme activities and lipid profile in streptozotocin-induced diabetic rats by supplementation of dandelion water extract. Clinica chimica acta 317: 109-117.

32. Bastar I, Seckin S, Uysal M, Aykac-Toker G (1998) Effect of streptozotocin on glutathione and lipid peroxide levels in various tissues of rats. Res Commun Mol Pathol Pharmacol 102: 265-272.

33. Borchgrevink CF, Andersen R, Hall J, Hatteland K, Ursin-Holm A (1960) "Premarin" as a Haemostatic Agent: Failure to Demonstrate Any Laboratory or Clinical Effect. Br Med J 2: 1645-1647.

34. Kamata K, Mitsuya M, Nishimura T, Eiki J, Nagata Y (2004) Structural basis for allosteric regulation of the monomeric allosteric enzyme human glucokinase Structure 12: 429-438.

35. Vestergaard H, Bjorbaek C, Hansen T, Larsen FS, Granner DK, et al. (1995) Impaired activity and gene expression of hexokinase II in muscle from noninsulin-dependent diabetes mellitus patients. J Clin Invest 96: 2639-2645.

36. Li Y, Qian ZJ, Ryu B, Lee SH, Kim MM, et al. (2009) Chemical components and its antioxidant properties in vitro: an edible marine brown alga, Ecklonia cava Bioorg Med Chem 17: 1963-1973.

37. Scalbert A, Manach C, Morand C, Remesy C, Jimenez L (2005) Dietary polyphenols and the prevention of diseases. Crit Rev Food Sci Nutr 45: 287 306.

38. Pari L, Murugan P (2007) Changes in glycoprotein components in streptozotocin-nicotinamide induced type 2 diabetes: influence of tetrahydrocurcumin from Curcuma longa. Plant Foods Hum Nutr 62: 25-29. 
Citation: Nazari M, Hajizadeh MR, Eftekhar A, Fattahpour S, Ziaaddini H, et al. (2014) Comparative Regulatory Effects of Morus Alba Leaf Extracts on Hepatic Enzymes in Streptozotocin-Induced Diabetic and Non-Diabetic Rats. Med chem S1: 003. doi:10.4172/2161-0444.S1-003

Page 6 of 6

39. Miura Y, Chiba T, Tomita I, Koizumi H, Miura S, et al. (2001) Tea catechins prevent the development of atherosclerosis in apoprotein E-deficient mice. J Nutr 131: 27-32.

40. Lambert JD, Hong J, Yang GY, Liao J, Yang CS (2005) Inhibition of carcinogenesis by polyphenols: evidence from laboratory investigations. Am J Clin Nutr 81: 284S-291S.

41. Dimitrakoudis D, Vranic M, Klip A (1992) Effects of hyperglycemia on glucose transporters of the muscle: use of the renal glucose reabsorption inhibitor phlorizin to control glycemia. J Am Soc Nephrol 3: 1078-1091.
42. Waltner-Law ME, Wang XL, Law BK, Hall RK, Nawano M, et al. (2002) Epigallocatechin gallate, a constituent of green tea, represses hepatic glucose production. J Biol Chem 277: 34933-34940.

43. Cheng JT, Liu IM (2000) Stimulatory effect of caffeic acid on alpha1Aadrenoceptors to increase glucose uptake into cultured $\mathrm{C} 2 \mathrm{C} 12$ cells. Naunyn Schmiedebergs Arch Pharmacol 362: 122-127.

44. Ohno T, Kato N, Ishii C, Shimizu M, Ito Y, et al. (1993) Genistein augments cyclic adenosine 3 '5'-monophosphate(cAMP) accumulation and insulin release in MIN6 cells. Endocr Res 19: 273-285. 